\title{
A standardised terminology of the embryonic envelopes and associated developmental stages of tapeworms (Platyhelminthes: Cestoda)
}

\author{
David Bruce Conn ${ }^{1}$ and Zdzisław Świderski ${ }^{2,3}$ \\ ${ }^{1}$ School of Mathematical and Natural Sciences, Berry College, Mount Berry, Georgia 30149-5036, USA; \\ ${ }^{2}$ W. Stefański Institute of Parasitology, Polish Academy of Sciences, 51/55 Twarda Str., 00-818 Warsaw, Poland; \\ ${ }^{3}$ Department of General Biology and Parasitology, Medical University of Warsaw, 5 Chałubińskiego Str., 02-004 Warsaw, \\ Poland
}

Key words: Cestoda, coracidium, embryogenesis, hexacanth, embryonic envelope, oncosphere

\begin{abstract}
Over the past 40 years, much has been published on the ultrastructure and cellular development of embryonic structures in a wide range of cestodes. However, the literature contains many discrepancies in both terminology and interpretations because of the facts that these organisms are phylogenetically diverse within their respective orders and families, the habitats that affect embryonic envelope structure are diverse, and the work has been done in various laboratories around the world. This review and synthesis was initiated by a working group of biologists from around the world convened at the Fifth International Workshop on Cestode Systematics and Phylogeny in České Budějovice, at the Institute of Parasitology of the Biology Centre, Academy of Sciences of the Czech Republic. It brings together the data from published work and establishes a uniform terminology and interpretation based on the data as they are presented. A consensus was reached for standardised definitions of the oncosphere, hexacanth, coracidium, embryonic envelopes, outer envelope, inner envelope, embryophore, vitelline capsule, shell, and outer coat. All of these are defined as components of the embryo or its vitellocyte-derived or uterine-derived coatings.
\end{abstract}

As basal protostomes, members of the phylum Platyhelminthes typically undergo unequal holoblastic cleavage conforming primitively to a spiralian plan that is apparent among the archoophoran turbellarians (Conn 2000, 2004a). However, the derived neoophoran flatworms, which include some turbellarian groups as well as the Digenea, Aspidogastrea, Monogenea, and Cestoda, have a cleavage pattern unlike any other in the animal kingdom. Neoophorans are defined by the separation of their female germ line into ovaries and vitelline glands, producing oocytes and vitellocytes, respectively, which must come together at the time of fertilisation to restore the full complement of female germinal material to the developing embryo (Conn 2000). Among all cestodes that have been studied in this regard, this union results in a unique capsule that surrounds the fertilised oocyte, and thus the complete embryonic mass (Świderski et al. 1970, 2004a, Świderski and Conn 1999). However, the oocyte and vitellocyte never fuse, so cleavage involves only the zygote, which develops from the fertilised oocyte while the vitellocyte remains adjacent.

Cleavage of neoophoran embryos is unequal and holoblastic as in archoophorans, but differs from that of any other animal group in that the larva develops only from the micromeres, while the macromeres and mesomeres, respectively, form two unique syncytial layers that surround the micromere mass and, thus, ultimately the fully formed larva (Ogren 1956, Rybicka 1964a, b, 1966, 1973, Euzet and Mokhtar-Maamouri 1975, 1976, Coil 1972, 1979, 1984, 1986, Conn 2000). In cestodes and trematodes, these syncytial layers are generally referred to as embryonic envelopes, and may serve to protect the developing and fully formed larva by producing resistant layers intracellularly (inner envelope and outer envelope, varying with species), and/or by secreting resistant material externally (also varying with species) (Świderski 1968, 1972, Rybicka 1972, Conn 1985a, 1999, 2000, Chomicz 1993). In some aquatic groups, the inner envelope also provides motility for the larva by developing as a ciliated free-swimming larval stage, which must emerge from the outer envelope and shell before swimming (Berrada-Rkhami and Gabrion 1990, Świderski 1994a). When the oncosphere larva, including its surrounding embryonic envelopes, is ingested by a suitable host, the hexacanth emerges from the envelopes, penetrates host tissues, and begins metamorphosis into the juvenile metacestode stage (Jarecka 1975, Ubelaker 1980, 1983, Conn 2004c, Świderski 2007).

Because of the unique nature of neoophoran embryogeny, and the importance of larval survival to transmission of cestodes to new hosts, there has been much research on cestode eggs, and several reviews have been published (Lethbridge 1980, Ubelaker 1983, Burt 1986). Variation in cestode eggs, and the potential importance to the life cycle of the parasite, is conspicu- 
ous even at the light microscope level (Jarecka 1961). However, details of cellular development and variations can be observed only with electron microscopy; thus, there has been a growing body of literature on the ultrastructure of cestode embryonic and larval stages (Tkach and Świderski 1997, 1998, Świderski and Salamatin 2002, Młocicki et al. 2005b), as well as reproductive cells and organs that contribute to the embryo (Xylander 1987, 1988, Korneva 2002, Poddubnaya 2005a, b, c, Levron et al. 2007), over the last 40 years. Because the light microscopical and ultrastructural studies have been conducted on numerous species and by numerous authors over many years, many discrepancies in terminology and interpretation have arisen in the literature. Several reviews of the literature on related subjects for cestodes alone (Świderski 1975, Lethbridge 1980, Ubelaker 1983, Smyth and McManus 1989, Świderski and Conn 2004, Conn 2005), for trematodes and cestodes comparatively (Świderski 1981, 1994b, 1996, Świderski and Conn 2000, Conn 2007), and for Platyhelminthes as an entire phylum (Shinn 1993, Kearn 1998, Conn 2000) have been published, but inconsistencies in the use of terms persist. For this reason, an international group of cestodologists was convened as a Working Group on Embryonic and Larval Structures at the Fifth International Workshop on Cestode Systematics and Phylogeny in České Budejovice, at the Institute of Parasitology of the Biology Centre, Academy of Sciences of the Czech Republic in 2005, and charged with developing a consensus on standardised terminology. This report provides a glossary of standardised terms that emerged from the working group, with the understanding that all researchers present would adhere to these standards in future publications. It is hoped that other cestodologists and comparative zoologists will also adhere to this standardised terminology in the interest of improving accurate communication in the field.

\section{GLOSSARY OF TERMS}

Standard terms: Consensus was reached by all participants in the International Workshop on the following 10 definitions, thus standardising these terms.

Hexacanth - a six-hooked larva derived from micromeres, which is the definitive product of embryogenesis of a cestode, and that invades the first or sole intermediate host.

Oncosphere - a hexacanth enclosed by one or two embryonic envelopes.

Coracidium - a hexacanth enclosed only by a ciliated inner envelope that provides a mechanism for free swimming.

Embryonic envelopes - the two syncytial envelopes derived from blastomeres and completely enclosing developmental stages from the late cleavage embryo through the fully formed hexacanth larva.

Outer envelope - the outermost embryonic envelope, derived from macromeres and enclosing all other embryonic and larval components. This envelope generally undergoes apoptosis early in embryonic development, and prior to final morphogenesis of the hexacanth.

Inner envelope - the innermost embryonic envelope, derived from mesomeres and enclosing micromeres and ultimately the hexacanth. This envelope generally persists throughout embryonic and larval development, and thus may be considered part of the fully formed larva.

Embryophore - name applied both to the full ciliated inner envelope of a coracidium, and to a specialised intracellular proteinaceous lamina produced within the inner envelope of a cestode with a non-swimming oncosphere. (Note: some authorities prefer to distinguish the motile inner envelope of a coracidium by referring to it as a "ciliated embryophore".)

Vitelline capsule - a thin proteinaceous layer that forms from coalescence of material released by exocytosis from one or more vitellocytes near the time of fertilisation, and that quickly encloses the vitellocyte(s) along with a single oocyte and a single sperm. Depending on the species, this layer may or may not persist through embryogenesis.

Shell - sclerotin proteinaceous material that is secreted by vitellocytes and is deposited on the inner surface of the vitelline capsule prior to hardening by a polyphenol/quinone tanning process. This occurs in cestode species that have a large number of vitellocytes per oocyte (i.e., polylecithal). The hardened shell typically encloses the oncosphere outside the host.

Outer coat - proteinaceous or other material that is secreted by the oviduct and/or uterus and is deposited on the outer surface of the vitelline capsule in some cestode species that have one or few vitellocytes per oocyte (i.e., oligolecithal).

\section{DISCUSSION}

Structures described by all of these terms are illustrated schematically in Figs. 1-6. Their form and development differ considerably between polylecithal orders such as Diphyllobothriidea and Bothriocephalidea (both formerly Pseudophyllidea, see Brabec et al. 2006, Kuchta et al. 2007), Caryophyllidea, and Spathebothriidea (Figs. 1-3), and oligolecithal orders such as Cyclophyllidea, Proteocephalidea, and Tetraphyllidea (Figs. 4-6). Little is known about the embryonic and larval structures of other orders such as Trypanorhyncha, Diphyllidea, Nippotaeniidea, Tetrabothriidea, and Lecanicephalidea.

\section{Hexacanth}

The detailed ultrastructure of the hexacanths, emerged from or within their surrounding embryonic envelopes, has been studied for many species, among the cyclophyllideans within non-motile eggs (Młocicki et al. 2005a, 2006), as well as the bothriocephalideans with motile coracidia (Świderski and Mokhtar 1974, Korneva 1994, Świderski and Mackiewicz 2004). Hexacanth structure is complex and somewhat variable, and 
was not a subject of discussion in the present work group. Thus, it is not reviewed in detail here, but should be addressed in future workshops for standardisation of terminology. Likewise, comparisons between eucestode hexacanths and the decacanths (10-hooked larvae) of amphilinideans and gyrocotylideans should be topics of future workshops.

\section{Oncosphere and coracidium}

There remains some controversy regarding what constitutes a cestode larva. The hexacanth, having emerged from its embryonic envelopes, is the stage that actually invades host tissue and undergoes metamorphosis into the postlarval metacestode juvenile (Conn 2004c, Korneva 2004). However, because the embryonic envelopes are themselves derivatives of the blastomeres, and also play a critical role in transmission to the host, it is arguable that the entire oncosphere, defined here as including the hexacanth inside its surrounding envelopes, is the larva. This is the case whether considering a nonmotile hexacanth covered by both embryonic envelopes and all of the embryonic envelopes and vitelline capsule (e.g., cyclophyllideans and proteocephalideans), or a free-swimming coracidium that includes only the hexacanth covered by the inner envelope with ciliated embryophore (e.g., diphyllobothriideans and some bothriocephalideans). The consensus reached by the working group and presented in this paper is that only the hexacanth should be considered as the larva, despite the fact that it is derived only from micromeres. This is consistent with the vast majority of literature on comparative animal development, which clearly shows that loss of embryonic structures prior to the activation of a fully formed larva is common across many phyla (Conn $2000,2004 a, b)$. With the publication of the present report, we suggest that authors discontinue the practice of using the terms hexacanth and oncosphere interchangeably, and follow the distinction defined herein.

\section{Embryonic envelopes}

Embryonic envelopes derive their composite name not because they surround the embryo, but because as blastomere derivatives they are actually part of the developing embryo. Some authors prefer to differentiate the metabolically active blastomere-derived embryonic envelopes surrounding the developing embryo from the degenerating remnants of the outer envelope and fully differentiated inner envelope surrounding a fully formed, infective hexacanth, which may be referred to as "oncospheral envelopes" (Chomicz 1993, Chomicz et al. 1995a, b, c, 1997, Swiderski et al. 2004b, c, 2005). However, envelopes at all stages from the end of cleavage to the fully formed oncosphere are covered in the present paper as embryonic envelopes, so oncospheral envelopes would be an advanced-age subset of embryonic envelopes according to this standardised terminology. Similarly, embryonic envelopes as defined in the present paper would include the structures referred to as "egg envelopes" of trematodes and cestodes by some authors (Świderski 1994b, 1996). Thus, we recommend that all authors in the future use the standardised term of embryonic envelopes.

In all cestodes studied to date, both the outer and the inner embryonic envelopes are syncytial, and usually are associated with each other only by contact of their adjacent plasma membranes. However, in Mesocestoides lineatus, the envelopes are joined by distinct desmosomes (maculae adhaerentes) and gap junctions (maculae communicantes) (Conn et al. 1984, Conn 1988a). These intercellular junctions have been observed in the embryonic envelopes of this species, and may hold the entire embryonic mass together after the loss of the vitelline capsule early during embryogeny of this species. Interestingly, desmosomes are common throughout the animal kingdom, but in cestodes have been described in no location other than from the embryonic envelopes of $M$. lineatus. No intercellular junction of any type has been described in the embryonic envelopes of any other cestode species, although gap junctions, hemidesmosomes and septate junctions (often incorrectly called "septate desmosome", see review by Conn 1993b) do occur in some adult tissues (Conn and Rocco 1989, Conn 1993b). However, intercellular junctions are difficult to resolve except in high-resolution preparations (Conn 1993b), so future investigators should look carefully for such junctions, which are small and could be easy to miss, especially in studies where lower magnifications and/or lower resolutions are used.

\section{Outer envelope}

The outer envelope in most cestodes is simpler in structure than the inner envelope, and often undergoes apoptosis during late embryogeny (Pence 1967, 1970, Rybicka 1972, Conn 1988a, Swiderski and Tkach 1997a). However, in others it may produce specialised structures such as the "subcapsular lamina" described by Conn (1999) in Distoichometra bufonis, or the "zone of electron-dense aggregates" described by Chomicz (1993) in Diorchis spp. Likewise, the outer envelope may help to form the "subshell membrane" described by Rybicka (1972) in Hymenolepis diminuta, although Conn (1985b) proposed that a similar structure in Monoecocestus americanus might be formed by the contact association between the juxtaposed plasma membranes of the inner and outer envelopes. Clearly, there is need for more study of the features and variations of outer envelopes, and the terminology of these features should be standardised.

\section{Inner envelope}

Unlike the outer envelope, the inner envelope typically persists throughout embryonic development, and remains as a viable syncytial envelope even in the fully developed oncosphere (Świderski 1972, Conn et al. 1984, Conn 1985a, Świderski et al. 2001, 2004b). Whether ciliated or not, the inner envelope is always formed from blastomeres that do not give rise to an epi- 


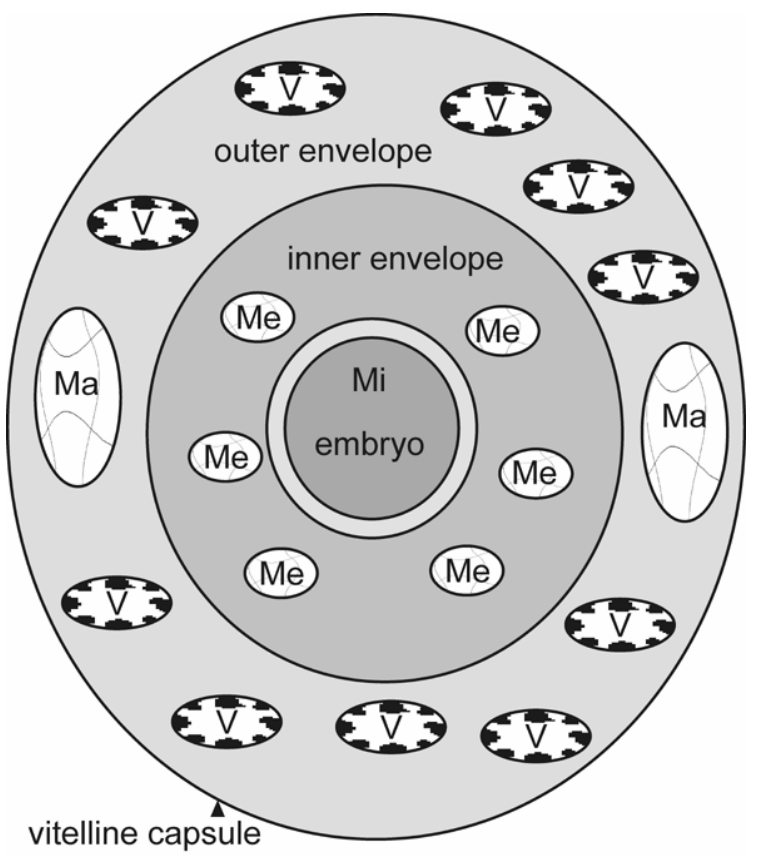

Fig. 1. Diagrammatic representation of a preoncosphere embryo in early cleavage of a cestode with polylecithal eggs (e.g., Diphyllobothriidea, Bothriocephalidea, Caryophyllidea, Spathebothriidea). The vitelline capsule, formed by secretions of numerous vitellocytes (V) at fertilisation, encloses the entire embryo and all of the vitellocytes. The vitellocytes still contain vesicles of shell precursor material. The outer envelope is a syncytium formed from the macromeres (Ma). The inner envelope is a syncytium formed from numerous mesomeres (Me). The embryo proper, from which the hexacanth larva will form, is a mass of dividing cells derived from the micromeres (Mi). All nuclei and organelles of both envelopes are active at this stage. The exact number of blastomeres of each type varies between species.

dermis or other ectodermal derivatives in phylogenetically more basal archoophoran flatworms that undergo typical spiralian cleavage (Conn 2000). Thus, the inner envelope is not homologous to an epidermis, though further studies of homologies among neoophoran flatworms are needed (Hartenstein and Jones 2003).

In those cestodes with coracidia, the inner envelope is synonymous with the ciliated embryophore, and engages in active swimming after emerging from the shell and apoptotic outer envelope (Świderski et al. 2005). In other cestodes, the inner envelope, while not motile, still maintains well-developed nuclei and organelles associated with protein synthesis, and appears to be metabolically active (Młocicki et al. 2005b). Also unlike the outer envelope, which is derived from only 2-3 macromeres in all species, the inner envelope is more variable in ontogeny. It is derived from only 3-4 mesomeres in cyclophyllideans, tetraphyllideans, and proteocephalideans (i.e., those with oligolecithal eggs) (Rybicka 1966, Euzet and Mokhtar-Maamouri 1975), but between 6 and 30 mesomeres in orders with polylecithal eggs (Świderski 1994b).

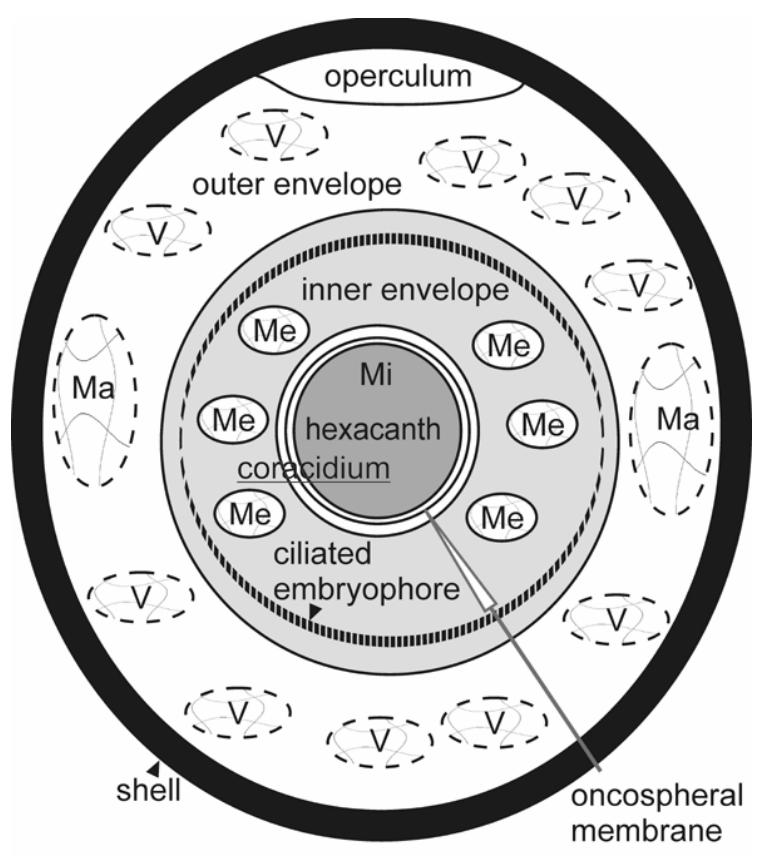

Fig. 2. Diagrammatic representation of a fully formed oncosphere of a cestode with polylecithal eggs and a ciliated embryophore (e.g., Diphyllobothriidea, some Bothriocephalidea). The vitelline capsule, formed by secretions of numerous vitellocytes (V) at fertilisation, becomes coated internally by shell precursors secreted from vitellocyte vesicles, and the vitellocytes have deteriorated. These species have a suture at one end of the shell, forming an operculum. The syncytial outer envelope derived from macromeres $(\mathrm{Ma})$, including all organelles, has deteriorated by apoptosis. The syncytial inner envelope derived from numerous mesomeres (Me) remains active, becoming a ciliated embryophore that, together with the enclosed hexacanth, constitute a coracidium, which will swim actively after emerging from the surrounding outer envelope remnant and shell, through the operculum. The oncospheral membrane has formed by membrane delamination between the inner envelope and hexacanth. The hexacanth, which is derived from micromeres (Mi) and is the only part that will invade the next host after it ingests the coracidium, is now fully formed. The exact number of formative blastomeres of each type, and the number of cells making up the final hexacanth, varies between species.

\section{Embryophore}

The intracellular embryophore produced as a proteinaceous lamina within the inner envelope of many cestodes is highly variable in thickness, ultrastructure and morphology, especially among the cyclophyllideans. Variations include thick embryophores made with blocks in taeniids (Morseth 1965, Nieland 1968, Beveridge et al. 1975, Chew 1983), thin embryophores with horizontal striae in Shipleya (Coil 1975) and Hepatocestus (Świderski et al. 2000), with radial striae in Dipylidium (Pence 1967), double layers in Oochoristica (Conn 1985a, Świderski and Subilia 1988) and in Joyeuxiella (Świderski et al. 2004b), pitted surfaces in Mesocestoides (Conn et al. 1984), discontinuous density in Dilepis (Świderski et al. 2004c) and other types. 
Some embryophores are even enlarged into various configurations such as polar filaments in Rodentolepis species (Conn and Kissel 1991, Conn 2000) or an elongated "pyriform apparatus" in some anoplocephalids (Conn 1985b, Swiderski et al. 2001). The functional significance, if any, of these variations is not known with certainty, and requires further study.

The term, embryophore, literally means "embryo carrier", and most aptly describes the ciliated inner envelope characteristic of diphyllobothriideans (Lumsden et al. 1974), and some bothriocephalideans (Świderski $1994 a, b)$. Because this feature is an entire modified inner envelope, and these forms typically do not have a thick intracellular lamina such as the embryophore of cyclophyllideans, it might be appropriate to refer to it as a ciliated envelope. The consensus of the working group was to retain the term, embryophore, because of its historical application and its functional role in the parasite life cycle. Nevertheless, adding an adjective, ciliated, to distinguish it as a ciliated embryophore would not violate the standardisation proposed in the present paper.

The exact nature of the embryophore among proteocephalideans remains enigmatic, primarily because of the paucity of ultrastructural studies. A distinct intracellular lamina within the inner envelope, like that of cyclophyllideans, often is not apparent at the light microscope level (e.g., see Scholz 1993, 1999), though a distinct double-layered embryophore has been demonstrated ultrastructurally in Proteocephalus longicollis by Świderski (1994c). The fact that the entire inner envelope may be very complex and responsive to immersion in water (Scholz 1991) further complicates the observation of these eggs. Embryonic envelope structure of tetraphyllideans has been scarcely studied, but available ultrastructural data indicate that an embryophore is present in at least two species (Mokhtar-Maamouri 1976).

\section{Vitelline capsule}

All cestodes and other neodermatan flatworms studied thus far have a vitelline capsule, secreted by the vitellocytes at fertilisation (Conn 1988c, Conn and Świderski 2004, Świderski et al. 2004a), and this capsule usually serves as the template for deposition of the shell or the outer coat. As noted above, M. lineatus is a cestode previously studied that loses its vitelline capsule early in embryogeny, although it is also lost from taeniids after exit from the host (Nieland 1968, Chew 1983). Future studies should examine other cestodes with paruterine organs to determine if vitelline capsule loss is widespread among such forms. The vitelline capsule persists in the nematotaeniids possessing paruterine organs and capsules that have been examined (Jones 1988, Świderski and Tkach 1997b, Conn 1999), but no study has been conducted on other groups with paruterine organs, such as the Paruterinidae.

The exact structural, chemical, and developmental nature of the vitelline capsule is not clear. It has been shown to originate from exocytosis of vitellocyte vesi- cles (Świderski and Conn 1999), and it often has at least two or three layers that vary between species and at different times shortly following fertilisation. It is associated with a membranous structure that has been referred to as a "labyrinth-like membrane" in Hymenolepis diminuta by Świderski et al. (1970), and "reticular mass" in Mesocestoides lineatus by Conn (1988a). In most cases, all layers of the vitelline capsule surround a single embryo with its associated vitellocyte(s) (Rybicka 1973, Bruňanská 1999, Świderski and Conn 1999, Conn et al. 2007). However, in M. lineatus, the vitelline capsule consists of one layer surrounding each embryo with associated vitellocyte(s), and the other layer surrounding a group of embryos with associated vitellocyte(s), binding them into embryo packets (Conn 1985c) or clusters. Conn (1988a) thus referred to these two layers as the "embryonic capsule" and the "cluster capsule", respectively. According to the standardised terminology established in the present paper, both should be regarded as components of the vitelline capsule.

Proteocephalideans have received little study of embryonic envelope ultrastructure relative to the other major oligolecithal order, the cyclophyllideans, and the tetraphyllideans have not been studied in this regard. The vitelline capsule of the proteocephalideans studied so far appears to differ from that of cyclophyllideans in being retained through development. Unlike cyclophyllideans, however, the few proteocephalideans studied thus far by electron microscopy appear to possess a vitelline capsule that undergoes swelling between the inner and outer layers as development progresses (Świderski and Subilia 1978, Bruňanská 1999, Conn et al. 2007). Using light microscopy only, CañedaGuzman et al. (2001) described "eggs in groups" in a proteocephalidean, Thaumasioscolex didelphidis, similar to the embryo clusters of the cyclophyllidean, $M$. lineatus (Conn 1988a), and referring to the outer layer bounding each group as a capsule. Without ultrastructural data, it is not possible to determine whether these are comparable. The genesis, development, and ultimate fate of the vitelline capsule requires much further ultrastructural study in all orders, especially regarding its variations among different cestode taxa. In particular, more study is needed of the vitelline capsule of cestode orders having polylecithal eggs, in which large numbers of vitellocytes with large shell precursor vesicles obscure the exact cellular source of the vitelline capsule. The nature of the Mehlis' gland's relationship to vitellocyte exocytosis and vitelline capsule and shell formation also requires more study.

Shell

Cestodes belonging to the more basal orders such as Diphyllobothriidea, Bothriocephalidea, Caryophyllidea, Spathebothriidea, and others are polylecithal, having many vitellocytes accompanying each oocyte and sperm at fertilisation (Mackiewicz 1968, Korneva 2001, Conn and Świderski 2004, Levron et al. 2007, Świderski and 




Fig. 3. Diagrammatic representation of a fully formed oncosphere of a cestode with polylecithal eggs but lacking a ciliated embryophore (e.g., Caryophyllidea, Spathebothriidea, some Bothriocephalidea). The vitelline capsule, formed by secretions of numerous vitellocytes $(\mathrm{V})$ at fertilisation, becomes coated internally by shell precursors secreted from vitellocyte vesicles, and the vitellocytes have deteriorated. Most of these cestodes do have operculated shells, but Eubothrium salvelini (Bothriocephalidea) lacks both cilia and an operculum, as well as an oncospheral membrane. The syncytial outer envelope derived from macromeres (Ma), including all organelles, has deteriorated by apoptosis. The syncytial inner envelope derived from numerous mesomeres (Me) lacks cilia and surrounds the hexacanth, which is derived from micromeres (Mi). The exact number of formative blastomeres of each type, and the number of cells making up the final hexacanth, varies between species.

Mackiewicz 2007a, b). In these groups, the vitellocytes contain large quantities of shell precursor material in secretory vesicles, which is released by exocytosis during embryonic development, and coalesces against the inside of the vitelline capsule, where it hardens into a shell of uniform thickness (Mackiewicz 1968, Yamane et al. 1983, Świderski and Xylander 2000, Poddubnaya et al. 2005b, c, Świderski et al. 2005, Levron et al. 2007). This is similar to the formation of shells in the trematodes (Conn and Etges 1983, Świderski 1994b, 1996). The present paper proposes that this structure should be referred to in the future as the standard simple term, "shell", rather than "eggshell" or "capsule" as some have referred to it in the past. Also, this term would apply equally to species with and without opercula (Figs. 2, 3).

\section{Outer coat}

Most cyclophyllideans that have been studied have a thick outer coat that has been shown by ultrastructural

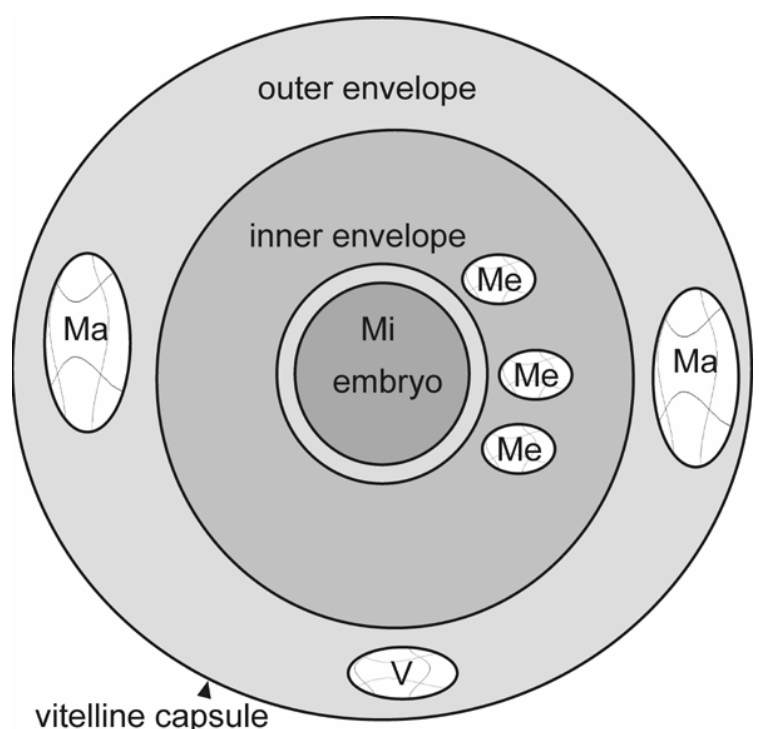

Fig. 4. Diagrammatic representation of a preoncosphere embryo in early cleavage of a cestode with oligolecithal eggs (e.g., Cyclophyllidea, Proteocephalidea, Tetraphyllidea). The vitelline capsule, formed by secretions of 1-2 vitellocytes (V) at fertilisation, encloses the entire embryo and vitellocyte(s), or rarely a cluster of embryos with associated vitellocytes. The outer envelope is a syncytium formed from 2-3 macromeres (Ma). The inner envelope is a syncytium formed from 3-4 mesomeres (Me). The embryo proper, from which the hexacanth larva will form, is a mass of dividing cells derived from the micromeres (Mi). All nuclei and organelles of both envelopes are active at this stage. The exact number of blastomeres of each type varies between species.

and histochemical methods to form primarily from uterine secretions that are added to the outer surface of the vitelline capsule, often resulting in ornamentation such as spikes (Conn 1985b) or knobs (Conn 1993a, Conn and Forman 1993). The nature of the outer coat in proteocephalideans is less clear since these have been studied primarily at early stages (Świderski and Subilia 1978, Bruňanská 1999, Korneva 2005, Conn et al. 2007). There is apparently some deposition of uterine secretion in members of this order (Bruňanská 1999) that parasitize anamniote hosts, but it does not reach the level seen in many terrestrial cyclophyllideans that parasitize amniote hosts. The fully formed outer coat of most cyclophyllideans is difficult to penetrate with fixatives and embedding resins, so many studies of cyclophyllidean embryonic envelopes are done with early developmental stages, leading to some uncertainty about final form (Fairweather and Threadgold 1981). In the taeniids, an exceptionally thick embryophore probably eliminates the need for further protection by an outer coat, which is never produced (Morseth 1965, Nieland 1968). Eggs of other cyclophyllideans with relatively thin outer coats are contained within protective maternal organs such as paruterine organs (Conn and Etges 1982a, Conn et al. 1984, Conn 1988b), paruterine capsules (Jones 1988, Świderski and Tkach 1997b), uterine 


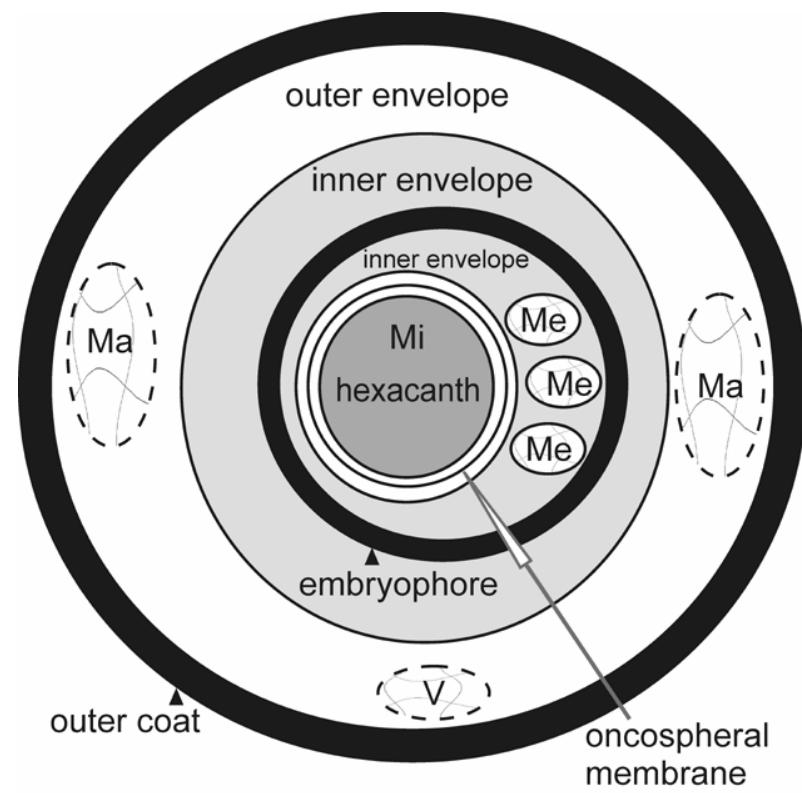

Fig. 5. Diagrammatic representation of a fully formed oncosphere of a cestode with oligolecithal eggs and belonging to the order Cyclophyllidea. The vitelline capsule, formed by secretions of 1-2 vitellocytes (V) at fertilisation, disappears altogether in some species, thickens in others, or becomes covered externally by uterine secretions to form the outer coat in others; the outer coat varies greatly in thickness between species. The syncytial outer envelope derived from macromeres (Ma), including all organelles, has deteriorated by apoptosis. The syncytial inner envelope derived from mesomeres (Me) remains active, forming the embryophore as an intracellular proteinaceous lamina. The oncospheral membrane has formed by membrane delamination between the inner envelope and hexacanth. The hexacanth, which is derived from micromeres (Mi) and is the only part that will invade the next host, is now fully formed. The exact number of formative blastomeres of each type, and the number of cells making up the final hexacanth, varies between species.

capsules (Conn and Etges 1982b, 1984), or parenchymatic capsules (Świderski and Tkach 2002). In Oochoristica (Conn 1985a) and Dipylidium (Pence 1967), the uterine lining, uterine secretion, and outer coat remain together outside the proglottid in the host's faeces. The terminology used to describe these various configurations, especially with respect to the parenchyma (Conn and Rocco 1989, Conn 1993b) and specialised uterine regions (Conn 1987a, b, 1993a, Conn and Forman 1990, 1993, Chomicz and Czubaj 1991, Chomicz 1996) should be a subject of examination and standardisation by a future working group.

Another structural feature common to most cestodes is the oncospheral membrane, which occurs as a thin membrane between the hexacanth and the inner envelope of fully formed oncospheres. Oncospheral membranes vary in number from one to two; they also may vary in form, but most have an appearance similar to that of a continuous septate junction, so that Conn

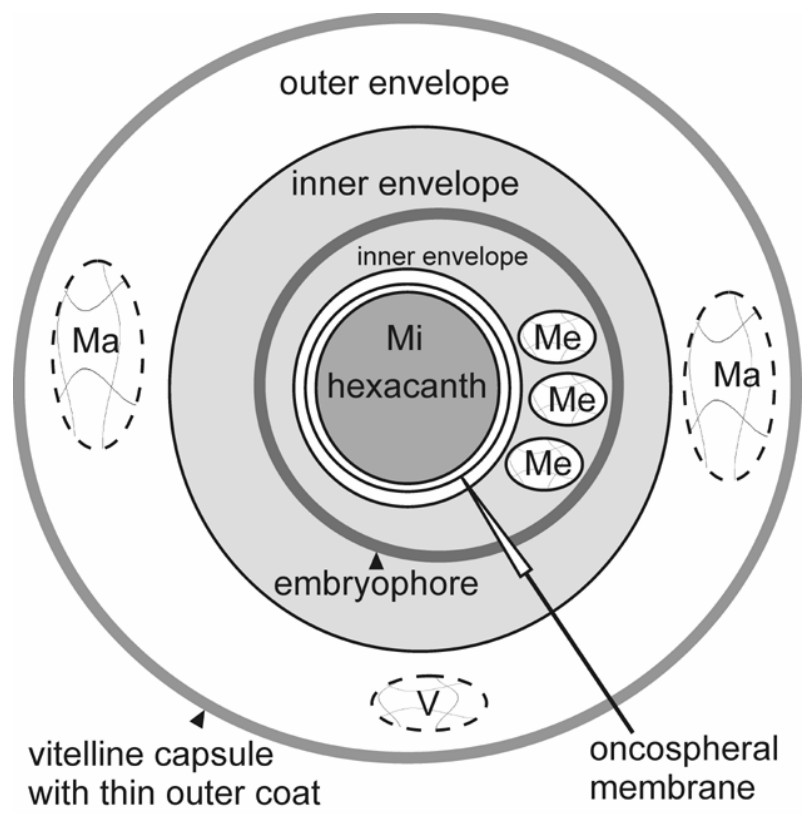

Fig. 6. Diagrammatic representation of a fully formed oncosphere of a cestode with oligolecithal eggs and belonging to the order Proteocephalidea (Tetraphyllidea is probably similar). The vitelline capsule, formed by secretions of 1-2 vitellocytes (V) at fertilisation, thickens by internal expansion in some species, and may become covered externally by a small amount of uterine secretions to form a thin coat. The syncytial outer envelope derived from macromeres (Ma), including all organelles, has deteriorated by apoptosis. The syncytial inner envelope derived from mesomeres (Me) remains active, forming the embryophore as an intracellular lamina. The oncospheral membrane has formed by membrane delamination between the inner envelope and hexacanth. The hexacanth, which is derived from micromeres (Mi) and is the only part that will invade the next host, is now fully formed. The exact number of formative blastomeres of each type, and the number of cells making up the final hexacanth, varies between species.

(1985b) proposed that they are a delaminated junction that initially binds the micromere mass to the embryonic envelopes. Chomicz and Walski (1991) and Chomicz (1993) showed a thick striated layer in embryos of Diorchis spp., referring to them as oncospheral membranes, although they are strikingly different from those of any other known species. Finally, the oncospheral membrane may be missing in some species (e.g., see Świderski et al. 2005). Future investigators and working groups should examine these and new cases, and standardise the terminology for this structure.

Other terms related to the embryos and larvae of cestodes require analysis and standardisation by a working group in the future. The treatment here is not intended to be exhaustive, even with respect to the 10 structures provided with standardised definitions here. However, this should provide a model, along with the report of Chervy (2002), for collaborative examination and interpretation of previously published work from 
disparate sources, leading to a better understanding of the processes and structural features under study, as well as communication with less ambiguity in future publications.

Acknowledgements. We are grateful to the Institute of Parasitology of the Biology Centre, Academy of Sciences of the Czech Republic for hosting the workshop on which this manuscript is based. We especially thank Tomáš Scholz, who served as the workshop's organiser and encouraged the development of the manuscript. We also thank other participants in the Fifth International Workshop on Cestode Systematics and Phylogeny, with special thanks to the Working Group on Embryonic and Larval Structures, Daniel Młocicki, Magdaléna Bruňanská, Michael D.B. Burt, Lena Jarecka, Louis Euzet, Larisa Poddubnaya, Tom Mattis, Jordi Miquel, Catarina Eira, Céline Levron, Vasyl Tkach, and Natalia Biserova.

\section{REFERENCES}

BERRADA-RKHAMI O., GABRION C. 1990: The fine structure of the embryonic envelopes before and after hatching in bothriocephalids: physiological and ecological significance. Parasitol. Res. 76: 251-262.

BEVERIDGE I., RicKard M.D., GREgORY G.G., Munday B.L. 1975: Studies on Anoplotaenia dasyuri Beddard, 1911 (Cestoda: Taeniidae), a parasite of the Tasmanian Devil: observations on the egg and metacestode. Int. J. Parasitol. 5: 257-267.

BRABEC J., KuChTA R., SCHOLZ T. 2006: Paraphyly of the Pseudophyllidea (Platyhelminthes: Cestoda): circumscription of monophyletic clades based on phylogenetic analysis of ribosomal RNA. Int. J. Parasitol. 36: 1535-1541.

BRUŇANSKÁ M. 1999: Ultrastructure of primary embryonic envelopes in Proteocephalus longicollis (Cestoda: Proteocephalidae). Helminthologia 36: 83-89.

BURT M.D.B. 1986: Early morphogenesis in the Platyhelminthes with special reference to egg development and development of cestode larvae. In: M.J. Howell (Ed.), Parasitology - Quo vadit? Australian Academy of Science, Canberra, pp. 241253.

CAÑEDA-GUZMÁN I.C., DE CHAMBRIER A., SCHOlZ T. 2001: Thaumasioscolex didelphidis n. gen., n. sp. (Eucestoda: Proteocephalidae) from the black-eared opossum Didelphis marsupialis from Mexico, the first proteocephalidean tapeworm from a mammal. J. Parasitol. 87: 639-646.

CHERVY L. 2002: The terminology of larval cestodes or metacestodes. Syst. Parasitol. 52: 1-33.

CHEW M.W.K. 1983: Taenia crassiceps: ultrastructural observations on the oncosphere and associated structures. J. Helminthol. 57: 101-113.

CHOMICZ L. 1993: Ultrastructural studies on the oncospheral envelopes of six species of genus Diorchis (Cyclophyllidea, Hymenolepididae). Acta Parasitol. 38: 161-165.

CHOMICZ L. 1996: Comparative ultrastructural studies on uterusegg interrelations in some species of hymenolepidids (Cestoda) with aquatic life cycles. Acta Parasitol. 41: 191198.

Chomicz L., CieleckA D., WALSKi M., CzUBAJ A. 1997: Ultrastructural studies on the oncospheral envelopes of hymenolepidid cestode, Wardium aequabile (Rudolphi, 1810) Spassky et Spasskaya, 1954, in the final stage of infective egg formation. Acta Parasitol. 42: 40-45.

Chomicz L., CzuBAJ A. 1991: Transmission electron micrograph studies of developing oncospheral envelopes of Fimbriaria fasciolaris (Hymenolepididae). Parasitol. Res. 77: 503-508.

CHOMICZ L., GRYTNER-ZIECINA B. WALSKI M. 1995a: Morphological studies on envelopes of oncospheres of the hymenolepidid cestode, Fimbriaria fasciolaris (Pallas, 1781). Acta Parasitol. 40: 26-30.

ChOMICZ L., Świderski Z., CzUBAJ A. 1995b: Ultrastructure of the oncospheral envelopes in Hymenolepididae (Cestoda) with aquatic life cycles. Hydrobiologia 305: 213-216.
CHOMICZ L., ŚWIDERSKI Z., GRYTNER-ZIECINA B. 1995c: Ultrastructure of the oncospheral envelopes and their differentiation in the cestode, Dicranotaenia coronula (Dujardin, 1845) (Cyclophyllidea, Hymenolepididae). Acta Parasitol. 40: 3136.

CHOMICZ L., WALSKI M. 1991: Ultrastructure of oncospheral envelopes of Diorchis elisae (Skrjabin, 1914) Spassky et Frese, 1961 (Cestoda, Hymenolepididae). Parasitol. Res. 77: $550-552$.

COIL W.H. 1972: Studies on the dioecious tapeworm Gyrocoelia pagollae with emphasis on bionomics, oogenesis, and embryogenesis. Z. Parasitenkd. 39: 183-194.

COIL W.H. 1975: The histochemistry and fine structure of the embryophore of Shipleya inermis (Cestoda). Z. Parasitenkd. 48: 9-14.

COIL W.H. 1979: Studies on the embryogenesis of the tapeworm Cittotaenia variabilis (Stiles, 1895) using transmission and scanning electron microscopy. Z. Parasitenkd. 59: 151-159.

COIL W.H. 1984: Studies on the development of Dioecocestus acotylus (Cestoda) with emphasis on the scanning electron microscopy of embryogenesis. Proc. Helminthol. Soc. Wash. 51: 113-120.

COIL W.H. 1986: The early embryology of Hymenolepis diminuta (Cestoda). Proc. Helminthol. Soc. Wash. 53: 38-47.

CONN D.B. 1985a: Fine structure of the embryonic envelopes of Oochoristica anolis (Cestoda: Linstowiidae). Z. Parasitenkd. 71: 639-648.

CONN D.B. 1985b: Scanning electron microscopy and histochemistry of embryonic envelopes of the porcupine tapeworm, Monoecocestus americanus (Cyclophyllidea: Anoplocephalidae). Can. J. Zool. 63: 1194-1198.

CONN D.B. 1985c: Fine structure of the embryo packets and uterus of Mesocestoides lineatus (Cestoda: Cyclophyllidea). Trans. Am. Microsc. Soc. 104: 106.

CONN D.B. 1987a: Fine structure, development and senescence of the uterine epithelium of Mesocestoides lineatus (Cestoda: Cyclophyllidea). Trans. Am. Microsc. Soc. 106: 63-73.

CONN D.B. 1987b: Synchronism of maternal uterine development and late embryogenesis of Oochoristica anolis (Cestoda: Cyclophyllidea). Trans. Am. Microsc. Soc. 106: 97-98.

CONN D.B. 1988a: Development of the embryonic envelopes of Mesocestoides lineatus (Cestoda: Cyclophyllidea). Int. J. Invertebr. Reprod. Devel. 14: 119-130.

CONN D.B. 1988b: The role of cellular parenchyma and extracellular matrix in the histogenesis of the paruterine organ of Mesocestoides lineatus (Platyhelminthes: Cestoda). J. Morphol. 197: 303-314.

CONN D.B. 1988c: Are vitelline cell globules a mechanism for polyspermy prevention in cyclophyllidean cestodes? Trans. Am. Microsc. Soc. 107: 106.

CONN D.B. 1993a: Ultrastructure of the gravid uterus of $H y$ menolepis diminuta (Platyhelminthes: Cestoda). J. Parasitol. 79: 583-590. 
CONN D.B. 1993b: The biology of flatworms (Platyhelminthes): Parenchyma cells and extracellular matrices. Trans. Am. Microsc. Soc. 112: 241-261.

CONN D.B. 1999: Ultrastructure of the embryonic envelopes and associated maternal structures of Distoichometra bufonis (Platyhelminthes: Cestoidea: Nematotaeniidae). Acta Parasitol. 43: 4-10.

CONN D.B. 2000: Atlas of Invertebrate Reproduction and Development, 2nd Edition. John Wiley \& Sons, Inc., New York, $315 \mathrm{pp}$.

CONN D.B. 2004a: Reproduction, development, and life history. In: Grzimek's Animal Life Encyclopedia, 2nd Edition. Vol. 1: Lower Metazoans and Lesser Deuterostomes. Gale Group Publishers, Farmington Hills, Michigan, pp. 15-24.

CONN D.B. 2004b: Reproduction, development, and life history In: Grzimek's Animal Life Encyclopedia, 2nd Edition. Vol. 2: Protostomes. Gale Group Publishers, Farmington Hills, Michigan, pp. 15-24.

CONN D.B. 2004c: Comparative aspects of postembryonic development of cestodes (Platyhelminthes) and other animal taxa. In: S. Mas-Coma (Ed.), Multidisciplinarity for Parasites, Vectors and Parasitic Diseases: Proceedings of the IX European Multicolloquium of Parasitology. Vol. 1. Articles of Keynote Speakers. Monduzzi Editore, Bologna, Italy, pp. 319-325.

CONN D.B. 2005: Glossary of cestode embryonic and larval structures. Wiad. Parazytol. 51: 266.

CONN D.B. 2007: Recent advances in the reproductive and developmental biology of Trematoda and Cestoda. Wiad. Parazytol. 53 (Suppl.): 6

CONN D.B., ETGES F.J. 1982a: Fine structure of mature eggs and paruterine organ of Mesocestoides sp. (Cestoda). Mol. Biochem. Parasitol. 5 (Suppl.): 705-706.

CONN D.B., ETGES F.J. 1982b: Fine structure of strobilar tegument, parenchyma and egg capsules of Oochoristica anolis (Cestoda: Linstowiidae). Am. Zool. 22: 951.

CONN D.B., ETGES F.J. 1983: Inhibition of egg production in an anomalous Plagitura salamandra Holl, 1928 (Trematoda: Plagiorchiidae). J. Parasitol. 69: 784-786.

CONN D.B., ETGES F.J. 1984: Fine structure and histochemistry of the parenchyma and uterine egg capsules of Oochoristica anolis (Cestoda: Linstowiidae). Z. Parasitenkd. 70: 769-779.

CONN D.B., ETGES F.J., SIDNER R.A. 1984: Fine structure of the gravid paruterine organ and embryonic envelopes of Mesocestoides lineatus (Cestoda). J. Parasitol. 70: 68-77.

CONN D.B., FORMAN L.A. 1990: Structural relationships between the eggs, uterine epithelium, and musculoparenchyma of $\mathrm{Hy}$ menolepis diminuta and Hymenolepis citelli (Platyhelminthes: Eucestoda). Trans. Am. Microsc. Soc. 109: 116-117.

CONN D.B., FORMAN L.A. 1993: Morphology and fine structure of the gravid uterus of three hymenolepidid tapeworm species (Platyhelminthes: Cestoda). Invertebr. Reprod. Devel. 23: 95103.

CONN D.B., KISSEL G.E. 1991: Ultrastructure of the embryonic envelopes of tapeworms of the genus Vampirolepis (Platyhelminthes: Cyclophyllidea: Hymenolepididae). Trans. Am. Microsc. Soc. 110: 86-87.

CONN D.B., MŁOCICKI D., ŚWIDERSKi Z. 2007: In-utero embryogenesis and uterine structure of Corallobothrium fimbriatum (Cestoda: Proteocephalidea) parasitic in Ictalurus nebulosus in the St. Lawrence River of North America. Parassitologia 49 (Suppl. 2): 389

CONN D.B., Rocco L.J. 1989: Fine structure of the cellular parenchyma and extracellular matrix of Ophiotaenia loennbergii (Cestoda: Proteocephalidea). Acta Zool. (Stockh.) 70: 105110
CONN D.B., ŚWIDERSKI Z. 2004: Fertilization in the parasitic Platyhelminthes. Wiad. Parazytol. 50 (Suppl.): 15.

EuZET L., MOKHTAR-MAAMOURI F. 1975: Développement embryonnaire de trois Cestodes du genre Acanthobothrium (Tetraphyllidea, Onchobothriidae). Ann. Parasitol. Hum. Comp. 50: 675-690.

EuZET L., MOKHTAR-MAamouri F. 1976: Développement embryonnaire de deux Phyllobothriidae (Tetraphyllidea, Onchobothriidae). Ann. Parasitol. Hum. Comp. 51: 309-327.

FAIRWEATHER I., THREADGOLD L.T. 1981: Hymenolepis nana: the fine structure of the embryonic envelopes. Parasitology 82: $429-443$.

HARTENSTEIN V., JONES M. 2003: The embryonic development of the bodywall and nervous system of the cestode flatworm Hymenolepis diminuta. Cell Tissue Res. 311: 427-435.

JARECKA L. 1961: Morphological adaptations of tapeworm eggs and their importance in the life cycles. Acta Parasitol. Pol. 9: 409-426.

JARECKA L. 1975: Ontogeny and evolution of cestodes. Acta Parasitol. Pol. 23: 93-114.

JONES M.K. 1988: Formation of the paruterine capsules and embryonic envelopes in Cylindrotaenia hickmani (Jones, 1985) (Cestoda: Nematotaeniidae). Aust. J. Zool. 36: 545-563.

KEARN G.C. 1998: Parasitism and the Platyhelminthes. Chapman and Hall, London, $544 \mathrm{pp}$

KORNEVA Zh.V. 1994: Cell compound and ultrastructural organisation of the coracidium of Triaenophorus nodulosus (Cestoda, Pseudophyllidea). Parazitologiya 28: 276-282. (In Russian.)

KORNEVA Zh.V. 2001: Vitellogenesis and capsule formation during embryogenesis in Triaenophorus nodulosus (Cestoda, Pseudophyllidea, Triaenophoridae). Zool. Zh. 80: 1422-1428. (In Russian.)

KORNEVA Zh.V. 2002: Fine structure of reproductive system in Nippotaenia mogurndae (Cestoda: Nippotaeniidae). Zool. Zh. 81: 266-275. (In Russian.)

KORNEVA Zh.V. 2004: Fine structure and development of Triaenophorus nodulosus (Cestoda) during metamorphosis: a review. Acta Zool. (Stockh.) 85: 59-68.

KORNEVA Zh.V. 2005: Placental type interactions and evolutionary trends of development of uterus in cestodes. J. Evol. Biochem. Physiol. 41: 552-560.

Kuchta R., SCHOlZ T., BRABEC J., BRAY R.A. 2007: Suppression of the tapeworm order Pseudophyllidea (Platyhelminthes: Eucestoda) and the proposal of two new orders, Bothriocephalidea and Diphyllobothriidea. Int. J. Parasitol. 38: 4955 .

LETHBRIDGE R.C. 1980: The biology of the oncosphere of cyclophyllidean cestodes. Helminthol. Abstr. Ser. A 49: 59-72.

LeVron C., Poddubnaya L.G., Kuchta R., Freeman M., ScHOLZ T. 2007: Vitellogenesis and vitelline system in the pseudophyllidean tapeworm Paraechinophallus japonicus: ultrastructural and cytochemical studies. Folia Parasitol. 54: 4350 .

LUMSDEN R.D., OAKS J.A., MUELLER J.F. 1974: Brush border development in the tegument of the tapeworm, Spirometra mansonoides. J. Parasitol. 60: 209-226.

MACKIEWICZ J.S. 1968: Vitellogenesis and egg-shell formation in Caryophyllaeus laticeps (Pallas) and Caryophylloides fennica (Schneider) (Cestoidea: Caryophyllidea). Z. Parasitenkd. 30: $18-32$.

MŁocicki D., ŚWiderski Z., ConN D.B., Eira C., Miquel J., BARANOWSKA-KORCZYC A. 2005a: Ultrastructure of oncospheral hook formation in the cestode Mosgovoyia ctenoides (Railliet, 1890) Beveridge, 1978 (Cyclophyllidea, Anoplocephalidae). Acta Parasitol. 50: 124-131. 
MŁOCiCKi D., Świderski Z., EiRA C., MiQuel J. 2005b: An ultrastructural study of embryonic envelope formation in the anoplocephalid cestode Mosgovoyia ctenoides (Railliet, 1890) Beveridge, 1978. Parasitol. Res. 95: 243-251.

MŁocicki D., Świderski Z., MiQuel J., EIra C., ConN D.B. 2006: Cellular organization of the oncosphere of Mosgovoyia ctenoides (Cestoda: Anoplocephalidae). J. Parasitol. 92: 953961.

MOKHTAR-MAAMOURI F. 1976: Études ultrastructurales de la gamétogenèse et des premiers stades du développement de deux cestodes Tetraphyllidea. Thèse d'état, Universitè des Sciences et Techniques du Languedoc, Montpellier II, France.

MORSETH D.J. 1965: Ultrastructure of developing taeniid embryophores and associated structures. Exp. Parasitol. 16: 207216.

NiELAND M.L. 1968: Electron microscope observations on the egg of Taenia taeniaeformis. J. Parasitol. 5: 957-969.

OGREN R.E. 1956: Development and morphology of the oncosphere of cestode Mesocestoides corti, a tapeworm of mammals. J. Parasitol. 42: 414-428.

PENCE D.B. 1967: The fine structure and histochemistry of the infective eggs of Dipylidium caninum. J. Parasitol. 53: 10411054.

PenCE D.B. 1970: Electron microscope and histochemical studies on the eggs of Hymenolepis diminuta. J. Parasitol. 56: 84-97.

PODDUBNAYA L.G., MACKIEWICZ J.S., BRUŇANSKÁ M., DEZFUL B.S. 2005a: Fine structure of the male reproductive ducts, vagina and seminal receptacle of Cyathocephalus truncatus (Cestoda: Spathebothriidea), from salmonid fish. Folia Parasitol. 52: 241-250.

PODDUBNAYA L.G., MACKIEWICZ J.S., BRUŇANSKÁ M., SCHOLZ T. 2005b: Ultrastructural studies on the reproductive system of progenetic Diplocotyle olrikii (Cestoda, Spathebothriidea): ovarian tissue. Acta Parasitol. 50: 199-207.

PODDUBNAYA L.G., MACKIEWICZ J.S., BRUŇANSKÁ M., SCHOLZ T. 2005c: Fine structure of the female reproductive ducts of Cyathocephalus truncatus (Cestoda: Spathebothriidea), from salmonid fish. Folia Parasitol. 52: 323-338.

RYBICKA K. 1964a: Gametogenesis and embryonic development of Dipylidium caninum. Exp. Parasitol. 4: 293-313.

RYBICKA K. 1964b: Embryonic development of Moniezia expansa (Rud., 1810) (Cyclophyllidea, Anoplocephalidae). Acta Parasitol. 12: 313-325.

RYBICKA K. 1966: Embryogenesis in cestodes. Adv. Parasitol. 4: 107-186.

RYBICKA K. 1972: Ultrastructure of embryonic envelopes and their differentiation in Hymenolepis diminuta (Cestoda). J. Parasitol. 58: 849-863.

RYBICKA K. 1973: Ultrastructure of macromeres in the cleavage of Hymenolepis diminuta (Cestoda). Trans. Am. Microsc. Soc. 92: 241-255.

SCHOLZ T. 1991: Studies on the development of the cestode Proteocephalus neglectus La Rue, 1911 (Cestoda: Proteocephalidae) under experimental conditions. Folia Parasitol. 38: 39 55.

SCHOLZ T. 1993: Development of Proteocephalus torulosus in the intermediate host under experimental conditions. J. Helminthol. 67: 316-324

SCHOLZ T. 1999: Life cycles of species of Proteocephalus, parasites of fishes in the Palearctic Region: a review. J. Helminthol. 73: 1-19.

SHINN G.L. 1993: Formation of egg capsules by flatworms (phylum Platyhelminthes). Trans. Am. Microsc. Soc. 112: 18-34.

SMYTH J.D., MCMANUS D.P. 1989: The Physiology and Biochemistry of Cestodes. Cambridge University Press, Cambridge UK, $398 \mathrm{pp}$.
ŚWIDERSKI Z. 1968: Electron-microscopy of embryonic envelope formation by the cestode Catenotaenia pusilla. Exp. Parasitol. 23: 104-113.

ŚWIDERSKI Z. 1972: La structure fine de l'oncosphère du cestode Catenotaenia pusilla (Goeze, 1782) (Cyclophyllidea, Catenotaeniidae). La Cellule 69: 207-237.

ŚWIDERSKI Z. 1975: Comparative fine structure of cestode embryos. In: Z. Petrovic (Ed.), Proceedings of the 2nd European Multicolloqium of Parasitology, Trogir, Yugoslavia, pp. 265273.

ŚWIDERSKI Z. 1981: Reproductive and developmental biology of the cestodes. In: W.H.Clark, Jr. and T.S. Adams (Eds.), Advances in Invertebrate Reproduction. Elsevier/North Holland, Amsterdam, pp. 365-366.

ŚWIDERSKI Z. 1994a: Origin, differentiation and ultrastructure of egg envelopes surrounding the coracidia of Bothriocephalus clavibothrium (Cestoda, Pseudophyllidea). Acta Parasitol. 39: 73-81.

ŚWIDERSKI Z. 1994b: Homology and analogy in egg envelopes surrounding miracidia of Schistosoma mansoni and coracidia of Bothriocephalus clavibothrium. Acta Parasitol. 39: 123130.

ŚWIDERSKI Z. 1994c: Ultrastructure of infective eggs of Proteocephalus longicollis (Zeder, 1800) (Cestoda, Proteocephalidea). Proceedings of the 13th International Congress on Electron Microscopy. Vol. 3B: Applications in Biological Sciences. Paris, pp. 1427-1428.

ŚWIDERSKI Z. 1996: Comparative studies on the ultrastructure, homology and analogy of egg envelopes in trematodes and cestodes. Wiad. Parazytol. 42: 81-96. (In Polish.)

ŚWIDERSKI Z. 2007: Postembryonic development of tapeworms source of novel phylogenetic characters for analysis of cestode evolution: comparative TEM studies. Helminthologia 44: 130-136.

ŚWIDERSKI Z., BRUŇANSKÁ M., MŁOCICKI D., CONN D.B. 2005: Ultrastructure of the oncospheral envelopes in the pseudophyllidean cestode Eubothrium salvelini (Schrank, 1790). Acta Parasitol. 50: 312-318.

ŚWIDERSKI Z., CONN D.B. 1999: Ultrastructural aspects of fertilization in Proteocephalus longicollis, Inermicapsifer madagascariensis, and Mesocestoides lineatus (Platyhelminthes: Cestoda). Acta Parasitol. 44: 19-30.

ŚWIDERSKI Z., CONN D.B. 2000: Egg formation in trematodes and cestodes: comparative ultrastructural studies. Acta Parasitol. 45: 158.

ŚWIDERSKI Z., CONN D.B. 2004: The differentiation and functional ultrastructure of the parenchymatic egg envelopes: Their role in cestode embryogenesis. Wiad. Parazytol. 50 (Suppl.): 116-117.

ŚwiderSKi Z., CONN D.B., MiQuel J., MŁOCICKI D. 2004a: Fertilization in the cestode Gallegoides arfaai (Mobedi et Ghadirian, 1977) Tenora \& Mas-Coma, 1978 (Cyclophyllidea, Anoplocephalidae). Acta Parasitol. 49: 108-115.

ŚWIDERSKI Z., HugGEL H., SCHÖNENBERGER N. 1970: The role of the vitelline cell in the capsule formation during embryogenesis in Hymenolepis diminuta (Cestoda). Proceedings of the 7th International Congress on Electron Microscopy, Grenoble, pp. 669-670.

ŚWIDERSKI Z., MACKIEWICZ J.S. 2004: Ultrastructural studies on the cellular organisation of the coracidium of the cestode Bothriocephalus clavibothrium Ariola, 1899 (Pseudophyllidea, Bothriocephalidae). Acta Parasitol. 49: 116-139.

ŚWIDERSKI Z., MACKIEWICZ J.S. 2007a: Ovoviviparity in cestodes parasites of fishes. Parassitologia 49 (Suppl. 2): 393. 
ŚWIDERSKI Z., MACKIEWICZ J.S. 2007b: Ultrastructure of polylecithal and oligolecithal eggs of cestodes parasites of fishes: comparative TEM study. Parassitologia 49 (Suppl. 2): 394.

Świderski Z., MiQuel J., Agostini S., Conn D.B., ChOMicz L., GRYTNER-ZIĘCINA B. 2004b: Differentiation and ultrastructure of the oncospheral envelopes of the cestode Joyeuxiella echinorhyncoides (Sonsino, 1889) (Cyclophyllidea, Dipylidiidae). Acta Parasitol. 49: 201-216.

ŚWIDERSKI Z., MOKHTAR M. 1974: The fine structure of the coracidia of Bothriocephalus clavibothrium Ariola, 1899 (Cestoda, Pseudophyllidea). Proceedings of the 3rd International Congress of Parasitology, pp. 412-413.

ŚWIDERSKI Z., NDIAYE P.I., MiQUEL J., TKACH V.V., MARCHAND B., CHOMicz L., GRYTNER-ZiĘCINA B., SEREDA M.J. 2001: Ultrastructural study of the embryonic development of the anoplocephalid cestode Anoplocephaloides dentata, an intestinal parasite of Arvicolidae rodents. II. Differentiation and cellular organisation of the oncosphere. Acta Parasitol. 46: 171-185.

ŚWIDERSKI Z., SALAMATIN R.V. 2002: Spasskytaenia platyrhyncha: origin, differentiation and ultrastructure of egg envelopes surrounding invasive oncospheres. Proceedings of the 10th International Congress of Parasitology. Monduzzi Editore, Bologna, Italy, pp. 545-550.

ŚWIDERSKI Z., SALAMATIN R.V., GRYTNER-ZIĘCINA B., KORNYUSHIN V.V., CONN D.B. 2004c: Electron microscope study on oncospheral envelope morphogenesis in the dilepidid cestode, Dilepis undula (Schrank, 1788). Acta Parasitol. 49: 300-308.

ŚWIDERSKI Z., SUBILIA L. 1978: Electron microscopy of embryonic envelope formation by the cestode Proteocephalus longicollis (Zeder, 1800) (Proteocephalidea). Proceedings of the 9th International Congress of Electron Microscopy, Toronto 2: 444-445.

ŚWIDERSKI Z., SUBILIA L. 1988: Embryonic development of the cestode Oochoristica agamae Baylis, 1919 (Cyclophyllidea: Anoplocephalidae). In: V. Mangclaviraj (Ed.), Electron Microscopy - 1988: Proceedings of the 6th Asia-Pacific Congress and Workshop on Electron Microscopy, Bangkok, Thailand, pp. 699-700.

ŚWIDERSKI Z., TKACH V.V. 1997a: Ultrastructure of the infective eggs of the hymenolepidid cestode Ditestolepis tripartita (Zarnowski, 1955), a parasite of shrews. Acta Parasitol. 42: $46-54$.

Received 2 November 2007
ŚWIDERSKI Z., TKACH V.V. 1997b: Differentiation and ultrastructure of oncospheral and uterine envelopes in the nematotaeniid cestode, Nematotaenia dispar (Goeze, 1782). Int. J. Parasitol. 27: 1065-1074.

ŚWIDERSKI Z., TKACH V.V. 2002: Ultrastructure of embryonic development of Inermicapsifer madagascariensis (Cestoda, Anoplocephalidae) with emphasis on the cellular organisation of the infective eggs. Acta Parasitol. 47: 105-120.

ŚWIDERSKI Z., TKACH V.V., VAUCHER C. 2000: Fine structure of the infective eggs of the dilepidid cestode Hepatocestus hepaticus (Baer, 1932), a parasite of shrews. Acta Parasitol. 45: 71-82.

ŚWIDERSKI Z., XYLANDER W.E.R. 2000: Vitellocytes and vitellogenesis in cestodes in relation to embryonic development, egg production and life cycles. Int. J. Parasitol. 30: 805-817.

TKACH V.V., ŚWIDERSKI Z. 1997: Late stages of egg maturation in the cestode Pseudhymenolepis redonica Joyeux et Baer, 1935 (Cyclophyllidea, Hymenolepididae), a parasite of shrews. Acta Parasitol. 42: 97-108.

TKACH V.V., ŚWIDERSKI Z. 1998: Differentiation and ultrastructure of the oncospheral envelopes in the hymenolepidid cestode Staphylocystoides stefanskii (Zarnowski, 1954). Acta Parasitol. 43: 222-231.

UBELAKER J.E. 1980: Structure and ultrastructure of the larvae and metacestodes of Hymenolepis diminuta. In: H.P. Arai (Ed.), Biology of the Tapeworm Hymenolepis diminuta. Academic Press, London, pp. 59-156.

UBELAKER J.E. 1983: The morphology, development and evolution of tapeworm larvae. In: C. Arme and P.W. Pappas (Eds.), Biology of the Eucestoda. Vol. 1. Academic Press, London, pp. 235-296.

XYLANDER W.E.R. 1987: Ultrastructural studies on the reproductive system of Gyrocotylidea and Amphilinidea (Cestoda). II. Vitellaria, vitellocyte development and vitelloduct of Gyrocotyle urna. Zoomorphology 107: 293-297.

XYLANDER W.E.R. 1988: Ultrastructural studies on the reproductive system of Gyrocotylidea and Amphilinidea (Cestoda). I. Vitellarium, vitellocyte development and vitelloduct in $\mathrm{Am}$ philina foliacea (Rudolphi, 1819). Parasitol. Res. 74: 363370.

YAMANE Y., NAKAgawA A., MaKinO Y., HiRAI K. 1983: Diphyllobothrium latum: scanning electron microscopic study on the eggshell formation. Jpn. J. Parasitol. 32: 13-25. 